\section{Six Heat-tolerant Cultivars of Lisianthus}

\author{
Brent K. Harbaugh and John W. Scott \\ Gulf Coast Research and Education Center, University of Florida, 5007 60th \\ Street East, Bradenton, FL 34203
}

Additional index words. high temperature, rosette, potted flowering plants, Eustoma grandiflorum, Gentianaceae, plant breeding

'Maurine Blue' and 'Florida Blue' were released in 1995 as heat-tolerant cultivars of lisianthus [Eustoma grandiflorum (Raf.) Shinners; Gentianaceae] developed at the Univ. of Florida's Gulf Coast Research and Education Center, Bradenton (Harbaugh and Scott, 1996; Harbaugh et al., 1996). These are the first heat-tolerant cultivars whose seedlings can be grown at 28 to $31^{\circ} \mathrm{C}$ without rosetting. Seedlings of commercial cultivars of lisianthus form rosettes when grown at 25 to $28{ }^{\circ} \mathrm{C}$ (Harbaugh et al., 1992; Ohkawa et al., 1991). Rosetted plants have a basal cluster of leaves, very short internodes typical of biennials, and do not bolt or flower for 3 to 6 months without being exposed to $\leq 15$ to $18^{\circ} \mathrm{C}$ for 3 to 4 weeks (Ohkawa et al., 1994; Pergola, 1992). Semirosetted plants develop when seedlings are grown at a constant 22 to $25{ }^{\circ} \mathrm{C}$ or at $<22{ }^{\circ} \mathrm{C}$ nights with $>28{ }^{\circ} \mathrm{C}$ days. Although semirosetted plants have one or more side shoots that may elongate and flower, they flower unpredictably and are of poor quality as cut flowers or potted plants. Thus, commercial production of lisianthus for late spring or summer sales is limited by high temperatures in many areas. Fall plug production, to produce flowering plants for early spring sales, also is difficult due to rosetting caused by the interaction of high temperatures and short days (Harbaugh, 1995). 'Maurine Pink', 'Maurine Pink-Lilac', 'Maurine White', 'Maurine White-on-Blue', 'Maurine Light Blue', and 'Maurine Lilac' are heat-tolerant $F_{1}$ cultivars of lisianthus that have vegetative and flowering characteristics similar to 'Maurine Blue'.

\section{Origin}

'Maurine Pink' is a $\mathrm{F}_{1}$ hybrid resulting from crossing inbred lines UF94-190 and UF94-214 (Fig. 1A). UF94-190 was the $F_{6}$ selection of a cross between UF8-2 and UF857. UF8-2 was the $F_{1}$ selection of a cross between 'Yodel Pink'-2 and UF7-47. 'Yodel Pink'-2 was selected for its basal branching and vivid pink flower color. UF7-47 was a self-pollinated plant $\left(S_{1}\right)$ selected from 'Blue

Received for publication 18 Nov. 1996. Accepted for publication 17 Mar. 1997. Florida Agricultural Expt. Station Journal Series R-05450. We thank Nancy West for her excellent technical support. The cost of publishing this paper was defrayed in part by the payment of page charges. Under postal regulations, this paper therefore must be hereby marked advertisement solely to indicate this fact.
Poppy' for its short, lower branching habit and ability to flower in the summer $\left(35^{\circ} \mathrm{C}\right.$ day). UF8-57 was a $\mathrm{S}_{1}$ of 'Tosen' selected for its short, basal branching habit. UF94-214 was the $F_{6}$ selection of a cross between UF8-57 and 'Yodel Pink'-1. 'Yodel Pink'-1 was a selection that flowered after seedlings were exposed to $28^{\circ} \mathrm{C}$ in a growth chamber. In addition to its heat-tolerant characteristics, it was used because of its bellshaped flowers and overlapping petals.

'Maurine Pink-Lilac' is an $F_{1}$ hybrid resulting from crossing inbred lines UF94-214 and UF94-253 (Fig. 1B). UF94-253 was the $F_{7}$ selection of a cross between 'Miss Lilac'-1 and UF7-53. 'Miss Lilac'-1 was chosen for its lower branching and unusual pale lilac flowers. UF7-53 was an $S_{1}$ of 'Blue Poppy' selected for basal branching and summer heattolerance.

'Maurine White' is an $\mathrm{F}_{1}$ hybrid resulting from crossing inbred lines UF94-147 and UF94-237 (Fig. 1C). UF94-147 was the $F_{6}$ selection of a cross between 'Yodel Lilac'-1 and UF7-53. 'Yodel Lilac'-1 was selected for its white flowers with a red-purple center. UF94-237 was the $\mathrm{F}_{3}$ selection of a cross between UF9280 and UF92-5. UF92-80 was the $\mathrm{F}_{4}$ selection of a cross between 'Yodel Pink'-3 and 'Yodel Pink'-2. 'Yodel Pink'-3 was selected for its lower branching. UF92-5 was the $\mathrm{F}_{4}$ selection of a cross between UF7-53 and UF7-47.

'Maurine White-on-Blue' is an $\mathrm{F}_{1}$ hybrid resulting from crossing inbred lines UF94-170 and UF94163 (Fig. 1D). UF94-170 was the $F_{7}$ selection of a cross between 'Double Light Blue'-1 and UF7-53. 'Double Light Blue'-1 was chosen for its strong stems, basal branching, and large flowers. UF94-163 was the $\mathrm{F}_{3}$ of a cross between UF91-24 and UF91-53. UF91-24 was the $\mathrm{F}_{3}$ selection of a cross between 'Yodel Lilac'-1 and UF7-53. UF91-53 was the $F_{4}$ selection of a cross between 'Double Light Blue'-1 and UF7-53.

'Maurine Light Blue' is an $F_{1}$ hybrid resulting from crossing inbred lines UF94-163 and UF94-147 (Fig. 1E). 'Maurine Lilac' is the $F_{1}$ hybrid resulting from crossing inbred lines UF94-253 and UF94-147 (Fig. $1 F)$.

Growing conditions used to select seedlings for resistance to heat-induced rosetting during development of heat-tolerant parents included 1) production during summer months under greenhouse conditions at day temperatures $\geq 35^{\circ} \mathrm{C}, 2$ ) exposure of 3 - to 4 -week-old seedlings to $28{ }^{\circ} \mathrm{C}$ for 4 weeks for initial selections in early generations, and 3 ) exposure of 17 -day-old seedlings to $31{ }^{\circ} \mathrm{C}$ for 5
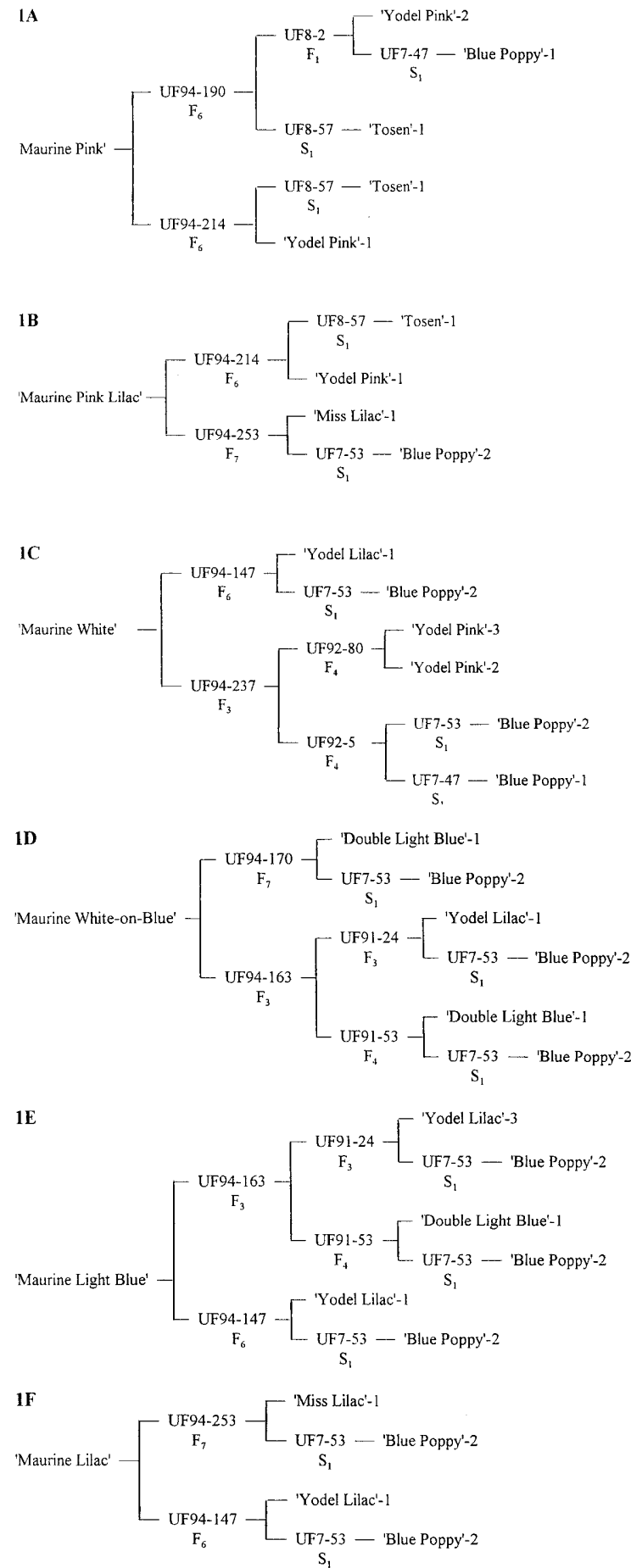

Fig. 1. Pedigrees of (A) 'Maurine Pink', (B) 'Maurine PinkLilac', (C) 'Maurine White', (D) 'Maurine White-on-Blue', (E) 'Maurine Light Blue', and (F) 'Maurine Lilac' lisianthus. 
weeks for final parent selections used in $F_{1}$ hybrids.

\section{Description}

Color was determined under natural light using the Royal Horticultural Society Colour Chart (Royal Horticultural Society, 1966). A number plus a letter are used for each color chip (e.g., 65B). Petals of lisianthus typically bear one color over most of the surface, but exhibit a distinct basal eyespot (i.e., base of petals surrounding the ovary) of a different color.

'Maurine Pink' has light pink petals (65B) on the adaxial petal surface. The abaxial petal surface is a lighter pink $(65 \mathrm{C})$. The eyespot is a dark red-purple (61A).

'Maurine Pink-Lilac' has dark pink adaxial petal surfaces with a lilac hue (75B), diffusing to a variegated 1.8 to $2 \mathrm{~cm}$ white band (155D) at the base of the petals. The abaxial petal surface is a slightly lighter shade of pink (75C). The eyespot is dark red-purple (61A).

The adaxial petal surface of 'Maurine White' is white (155D) at the petal margins, diffusing into a creamy yellow-white (157B) toward the petal's base. The abaxial petal surface is white (155D) from the petal margin to the base. The eyespot is a red-purple (59C).

The adaxial and abaxial petal surfaces of 'Maurine White-on-Blue' are white (155D). The eyespot is a dark blue (83B) that is quite distinct as compared to the red-purple eyespot of 'Maurine White'.

'Maurine Light Blue' has violet-blue petals (90B) on the adaxial petal surface, diffusing to a variegated 1.8 to $2 \mathrm{~cm}$ white band (155D) at the base of the petals. The abaxial petal surface is a lighter violet-blue (90D). The eyespot is a dark violet-blue (89B).

'Maurine Lilac' has pale lilac petals (69C) on the adaxial petal surface, diffusing to a variegated 1.8 to $2 \mathrm{~cm}$ white band (155D) at the base of the petals. The abaxial petal surface is a pale violet (69C). The eyespot is a dark red-purple $(64 \mathrm{~A})$.

\section{Characteristics and use}

The most important and distinguishing attribute of all the Maurine cultivars as compared with commercial lines is their heattolerance. Seeds of three Heidi cultivars and seven Maurine cultivars were planted on 13 Dec. 1995, at Bradenton, and 17-day-old seedlings were grown at a constant $31{ }^{\circ} \mathrm{C}$ for 5 weeks. The range in rosetting for Maurine cultivars was $0 \%$ to $10 \%$ (Table 1). However,

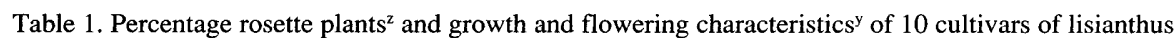
grown in $11.5-\mathrm{cm}$ square pots $(0.65-\mathrm{L})$ with capillary mat irrigation at Bradenton, Fla. No growth regulators were used.

\begin{tabular}{|c|c|c|c|c|c|c|c|}
\hline \multirow[b]{2}{*}{ Cultivar } & \multirow{2}{*}{$\begin{array}{c}\text { Rosette } \\
(\%)\end{array}$} & \multicolumn{2}{|c|}{ Plant ht $(\mathrm{cm})^{x}$} & \multicolumn{2}{|c|}{ No. lateral branchesw } & \multirow{2}{*}{$\begin{array}{c}\text { No. flowers } \\
\text { and buds }\end{array}$} & \multirow{2}{*}{$\begin{array}{c}\text { No. days to } \\
\text { flower }\end{array}$} \\
\hline & & 1 & 2 & Basal & Lower & & \\
\hline \multicolumn{8}{|c|}{ Maurine series } \\
\hline Blue & 0 & 65 & 84 & 4.6 & 6.2 & 44 & 149 \\
\hline Pink & 0 & 66 & 83 & 4.2 & 6.8 & 60 & 151 \\
\hline Dark Pink & 3 & 60 & 78 & 3.8 & 5.6 & 41 & 151 \\
\hline White & 0 & 59 & 75 & 3.6 & 12.2 & 57 & 152 \\
\hline White-on-Blue & 10 & 58 & 84 & 2.0 & 5.4 & 53 & 156 \\
\hline Lilac & 0 & 69 & 90 & 2.6 & 6.6 & 54 & 155 \\
\hline Light Blue & 0 & 75 & 102 & 0.0 & 5.0 & 39 & 156 \\
\hline \multicolumn{8}{|c|}{ Heidi series } \\
\hline Deep Blue & 100 & 65 & 96 & 1.0 & 4.4 & 34 & 150 \\
\hline Rose & 80 & 60 & 79 & 2.2 & 3.6 & 36 & 152 \\
\hline White & 100 & 64 & 77 & 0.8 & 6.0 & 46 & 154 \\
\hline $\mathrm{LSD}_{0.05}$ & & 10 & 9 & 1.4 & 2.0 & 13 & 5 \\
\hline
\end{tabular}

${ }^{\mathrm{z}}$ Seventeen-day-old seedlings were exposed to $31^{\circ} \mathrm{C}$ for 5 weeks in a growth chamber and evaluated after 4 weeks for percentage of rosette plants, $n=30$.

${ }^{y}$ Vegetative and flowering characteristics were for non-rosetted control plants grown in a fiberglass greenhouse with a high of 33 to $35^{\circ} \mathrm{C}$ (day) and low of 13 to $15^{\circ} \mathrm{C}$ (night). Values represent the means of five replications of single-plant experimental units arranged in a completely randomized design.

xPlant height 1 was the distance from the pot rim to the base of the first opened flower; plant height $2=$ distance from the pot rim to the tip of the highest bud measured after three flowers had opened.

${ }^{\text {w}}$ Basal branches were lateral stems originating at the first four to five leaf pairs (i.e., from the basal cluster of leaves below the bolted stem), and lower branches were lateral stems originating on the central flowering stem (bolted stem) above the basal leaves but below the first flower bud.

$80 \%$ to $100 \%$ of the Heidi cultivars rosetted.

In addition to heat-tolerance, we considered that these cultivars had enough similarities in vegetative and flowering characteristics in comparison wi ${ }^{\mathrm{TMTM}}$ th 'Maurine Blue' that they could be included in a "Maurine" series to expand the range of flower colors. Notable differences (Table 1) between 'Maurine Blue' and these six new cultivars when evaluated in 1996 were 1) 'Maurine Light Blue' was significantly taller than 'Marine Blue'; 2) 'Maurine Light Blue', 'Maurine White-onBlue', and 'Maurine Lilac' had fewer lower branches and flowered later than 'Maurine Blue'; and 3) 'Maurine White' had more lower branches and 'Maurine Pink' had more flowers and floral buds than 'Maurine Blue'.

Maurine cultivars are intended to be used as tall bedding plants or for flowering potted plants. Growth retardants are necessary for production of 'Maurine Blue' in 12- to 15-cmdiameter pots (Harbaugh and Scott, 1996). Three to four plugs per 12 - to $15-\mathrm{cm}$-diameter pot are suggested for optimal marketing display.

\section{Availability}

Plugs of these Maurine cultivars will be offered for sale through Earl J. Small Growers,
Pinellas Park, Fla. Scientists interested in seed for research purposes should contact B.K.H.

\section{Literature Cited}

Harbaugh, B.K. 1995. Flowering of Eustoma grandiflorum (Raf.) Shinn. cultivars influenced by photoperiod and temperature. HortScience 30:1375-1377.

Harbaugh, B.K., M.S. Roh, R.H. Lawson, and B. Pemberton. 1992. Rosetting of lisianthus cultivars exposed to high temperatures. HortScience $27: 885-887$

Harbaugh, B.K. and J.W. Scott. 1996. 'Maurine Blue' lisianthus [Eustoma grandiflorum (Raf.) Shinn.]. HortScience 31:1055-1056.

Harbaugh, B.K., J.W. Scott, and D.B. Rubino. 1996. 'Florida Blue' semi-dwarf lisianthus [Eustoma grandiflorum (Raf.) Shinn.]. HortScience 31:1057-1058.

Ohkawa, K., A. Kano, K. Kanematsu, and M. Korenaga. 1991. Effects of air temperature and time on rosette formation in seedlings of Eustoma grandiflorum (Raf.) Shinn. Scientia Hort. 48:171-176.

Ohkawa, K., T. Yoshizumi, M. Korenaga, and K. Kanematsu. 1994. Reversal of heat-induced rosetting in Eustoma grandiflorum with low temperatures. HortScience 29:165-166.

Pergola, G. 1992. The need for vernalization in Eustoma russellianum. Scientia Hort. 51:123127.

Royal Horticultural Society. 1966. Royal Horticultural Society colour chart. Royal Hort. Soc., London. 